Published in final edited form as:

J Psychiatr Res. 2018 September ; 104: 16-23. doi:10.1016/j.jpsychires.2018.06.007.

\title{
How Lipids May Affect Risk for Suicidal Behavior
}

\author{
Federico M. Daray, M.D., Ph.D.a, J. John Mann, M.D. ${ }^{b, c, d}$, and M. Elizabeth Sublette, M.D., \\ Ph.D. b,c, ${ }^{*}$ \\ alnstitute of Pharmacology. School of Medicine. University of Buenos Aires, Paraguay 2155, piso \\ 9, Ciudad Autónoma de Buenos Aires, Argentina, C1121ABG \\ bDepartment of Psychiatry, Columbia University, 1051 Riverside Drive, New York, NY 10032 \\ 'Division of Molecular Imaging \& Neuropathology, New York State Psychiatric Institute, 1051 \\ Riverside Drive, Unit 42, New York, NY 10032 \\ dDepartment of Radiology, Columbia University, 622 West $168^{\text {th }}$ St, New York, NY 10032
}

\begin{abstract}
Suicide and nonfatal suicidal behaviors are major causes of mortality and morbidity worldwide. Variability in rates of suicide and suicidal behaviors within and between countries has been attributed to population and individual risk factors, including economic status and cultural differences, both of which can have suicide risk effects mediated through a variety of factors, of which perhaps the least understood is the role of diet. We therefore review the scientific literature concerning two major dietary lipid classes, cholesterol and polyunsaturated fatty acids (PUFAs), that have been associated with higher risk of suicide attempts and suicide. We consider potential mechanistic intermediates including serotonin transporters and receptors, toll-like receptors (TLRs), nuclear factor kappa-light-chain-enhancer of activated B cells (NFkB), and peroxisome proliferator activated receptors (PPARs). Based on this review, we describe a theoretical model linking cholesterol and PUFA status to suicide risk, taking into account the effects of cholesterollowering interventions on PUFA balance, membrane lipid microdomains (rafts) as a nexus of interaction between cholesterol and omega-3 PUFAs, and downstream effects on serotonergic neurotransmission and specific inflammatory pathways.
\end{abstract}

\footnotetext{
* To whom correspondence should be addressed: New York State Psychiatric Institute, 1051 Riverside Drive, Unit 42, New York, NY 10032, Tel: 646 774-7514, Fax: 646 774-7589, Elizabeth.Sublette@ nyspi.columbia.edu.

Publisher's Disclaimer: This is a PDF file of an unedited manuscript that has been accepted for publication. As a service to our customers we are providing this early version of the manuscript. The manuscript will undergo copyediting, typesetting, and review of the resulting proof before it is published in its final citable form. Please note that during the production process errors may be discovered which could affect the content, and all legal disclaimers that apply to the journal pertain.

Conflict of Interest Statement

Dr. Mann receives royalties from Research Foundation for Mental Hygiene for commercial use of the C-SSRS. Drs. Daray and Sublette have no conflicts to report.
} 


\section{Introduction}

\subsection{Lipids and suicide}

Suicide and suicidal behaviors are among the leading causes of death and injuries worldwide. Approximately 800,000 people die from suicide each year, and suicide is the second leading cause of death in the 15-29 year-old cohort. Ten to twenty times more individuals attempt suicide, indicating that both suicide and non-fatal suicidal behaviors are prevalent and need to be addressed. (World Health Organization, 2014)

To understand the causes of suicide, prevalent explanatory models have focused on psychological factors such as feelings of thwarted belongingness, perceived burdensomeness, and hopelessness (Van Orden et al., 2010); neurobiological factors such as genetic risk, serotonergic functioning, and altered stress responses (Mann et al., 1999, Oquendo et al., 2014); and cultural factors (Chu et al., 2018).

Rates of suicide and suicidal behaviors vary geographically, with higher rates of suicide occurring in lower per capita-income regions (World Health Organization, 2017). Some portion of this variability may be attributable to economic and cultural differences that influence nutrition and in this way can impact the diathesis or predisposition to suicide behavior. One nutritional factor proposed to impact suicide and suicidal behavior is dietary lipid intake, presumably through lipid effects on brain. Two major lipid classes have been implicated in suicide risk, cholesterol and polyunsaturated fatty acids (PUFAs). We here review the evidence associating low cholesterol and low n-3 relative to n-6 PUFAs with suicide and suicidal behaviors. Finally, we present a neurobiological model proposing that the actions and interactions of cholesterol and PUFA status may influence suicide risk through effects on decreased serotonergic neurotransmission and/or increased inflammation (see Figure 1).

\subsection{Low cholesterol and suicide risk}

Cholesterol and cholesterol metabolites are abundant in the brain. Accounting for $2 \%$ of body weight, the brain has $25 \%$ of total body cholesterol (Dietschy and Turley, 2001). Cholesterol is essential for cell membrane stability and neurotransmission (Ghaemi et al., 2000). An association between cholesterol and suicide was first reported in a 1990 metaanalysis of primary intervention trials in cardiovascular illness, which found that cholesterol lowering treatments led to an excess in non-illness mortality, mostly suicide and injury (Muldoon et al., 1990). A second meta-analysis was carried out by the same group 11 years later, after hydroxymethylglutaryl-coenzyme A (HMG-CoA) reductase inhibitors, or statins, became the most commonly used cholesterol-lowering drug class. The authors concluded that overall, cholesterol-lowering treatments were not related to non-illness mortality, and that statins showed a tendency to reduce non-illness mortality (Muldoon, 2001). Non-statin treatments, however, including diet, did exhibit a trend $(p=0.06)$ toward increased mortality from suicide, accidents and trauma (Muldoon et al., 2001).

In parallel, observational studies of cholesterol status in psychiatric populations have been summarized recently in a meta-analysis of 65 epidemiological studies, involving 510,392 participants, studying associations between serum lipid levels and 'suicidality' (Wu et al., 
2016). Included were studies that assessed total serum cholesterol (TC), high-density lipoprotein cholesterol (HDL-C), low-density lipoprotein cholesterol (LDL-C) and/or triacylglycerols (TAG). The outcome measure of 'suicidality' was defined as including suicidal ideation, suicide attempt, having threatened suicide, or death by suicide. The main results were that TC and LDL-C levels were lower in suicidal patients than in non-suicidal patients and healthy controls; HDL-C levels were lower in suicidal patients than in healthy controls; and TG levels were lower in suicidal than in non-suicidal patients. When all three groups were pooled, lower serum TC was associated with higher risk of suicidality, suicide attempts, and suicide.

\subsection{Low dietary intake of polyunsaturated fatty acids and suicide risk}

Another lipid class implicated in suicide risk is polyunsaturated fatty acids (PUFAs), and it has been suggested that PUFA status may be an important factor in cholesterol associations with suicide risk (Hibbeln and Salem, 1996), as has also has been postulated for cardiovascular risk (de Lorgeril et al., 2005). Comprised of long carbon chains with two or more double bonds and categorized as n-3 or n- 6 based on the number of carbon atoms from the terminal methyl (omega) end to the first double bond of the carbon chain, PUFAs are found in every cell of the human body and present in multiple lipid classes: esterified to triacylglycerol, cholesterol (as cholesteryl esters) and phospholipids, as well as existing as non-esterified ('free') fatty acids (reviewed in (Jump, 2002)). Both n-3 and n-6 PUFAs are defined as essential because humans and most other mammals cannot synthesize these compounds de novo (Spector, 1999), although ingested shorter-chain fatty acids, alpha linolenic acid (ALA, 18:3n-3) and linoleic acid (LA, 18:2n-6) can be converted to longchain PUFAs in the liver through a series of elongation and desaturation reactions. In the modern diet, whereas n-6 PUFAs are abundant in many plant-based oils and in meat from animals fed corn-based diets, the major source of n-3 PUFAs is seafood (Meyer et al., 2003, Simopoulos, 2011).

Several studies have linked PUFAs with suicide risk. A case-control study of emergency room patients showed that red blood cell levels of eicosapentaenoic acid (EPA, 20:5n-3) were lower in suicide attempters in comparison with controls (Huan et al., 2004). In a pilot study, low docosahexaenoic acid (DHA, 22:6n-3) percentages of total phospholipid fatty acids and elevated n-6 to n-3 ratios predicted suicidal behavior in patients with major depression (Sublette et al., 2006). Finally, a large ( $n=1600)$ retrospective case-control study of active duty US military personnel determined that low n-3 PUFA levels were associated with increased risk of suicide compared with other causes of death (Lewis et al., 2011). Higher blood levels of $n-6$ PUFAs also have been reported in association with higher suicide risk and depression in a study of 234 pregnant women (Vaz et al., 2014).

Lower n-3 PUFA levels are also observed in depressed patients compared with healthy controls, in plasma (Dinan et al., 2009, Féart et al., 2008, Frasure-Smith et al., 2004, Rees et al., 2009, Tiemeier et al., 2003) and serum (Conklin et al., 2007, Maes et al., 1999, Riemer et al., 2010, Schins et al., 2007) phospholipids, red blood cell membranes (Adams et al., 1996, Amin et al., 2008, Edwards et al., 1998, McNamara et al., 2010b, Peet et al., 1998), and adipose tissue (Mamalakis, 2002, Mamalakis et al., 2006a, Mamalakis et al., 2006b, 
Papandreou et al., 2011, Sarri et al., 2008), and confirmed by meta-analytic findings (Lin et al., 2010). These relationships are relevant since depression is one of the main risk factors associated with suicidal behavior (Teti et al., 2014).

Another suicide risk factor, the presence of impulsive/aggressive traits (van Heeringen and Mann, 2014), also has been observed to associate with lower n-3 PUFAs. In patients with deliberate self-harm, correlations were seen between low plasma levels of n-3 PUFAs and higher impulsivity scores (Garland et al., 2007). In context of substance use disorders, another risk factor for suicide (Tondo et al., 1999), low plasma EPA, was associated with aggression and impulsivity in adults with MDD and comorbid substance use disorders (Beier et al., 2014); and lower plasma levels of docosapentaenoic acid (DPA, 22:5n-6), DHA, and total n-3 PUFAs were found in aggressive cocaine addicts (Buydens-Branchey et al., 2003). Of note, a low cholesterol diet in nonhuman primates also is associated with serotonin neurotransmitter system deficits and greater aggressive behavior (Kaplan et al., 1994).

Meta-analyses provide variable conclusions concerning the therapeutic benefits of n-3 PUFAs in depression (Appleton et al., 2006, Appleton et al., 2010, Appleton et al., 2015, Bloch and Hannestad, 2012, Grosso et al., 2014, Martins, 2009, Martins et al., 2012, Mocking et al., 2016, Sublette et al., 2011, Yang et al., 2015); disparities appear to stem from differences with regard to depression severity, selection of outcome measures, composition of n-3 PUFA supplements, and estimates of negative publication bias. There is considerable support for the finding that n-3 PUFA supplements have greatest efficacy in patients who have a diagnosis of major depression and when the $\mathrm{n}-3$ supplement contains a greater proportion of EPA compared to DHA (Appleton, 2010, Grosso, 2014, Martins, 2009, Martins, 2012, Sublette, 2011, Yang, 2015).

Given that both cholesterol and PUFAs have been implicated in suicide risk, Hibbeln \& Salem (Hibbeln and Salem, 1995, 1996) have suggested that PUFA status might be a confounder in the putative relationship between plasma cholesterol and suicide, citing effects of cholesterol-lowering medications on the n-3 to n-6 PUFA balance. We here expand on this idea, describing biochemical and pathophysiologic mechanisms in support of a mediation hypothesis that lowering cholesterol may increase risk of suicidal behavior at least in part through effects on PUFAs.

\section{Proposed model connecting cholesterol reduction with PUFA status and suicidal behavior}

To postulate a pathogenic and/or causal relationship between cholesterol, PUFAs and suicidal behavior, biological plausibility is needed. As described below and modeled in Figure 1, putative mechanisms include alteration of membrane lipid raft structure by the proportions of cholesterol and n-3 PUFAs, affecting the functioning of membrane-bound proteins including serotonin receptors and transporters, and toll-like receptors. Cholesterol lowering also can increase the n-6:n-3 PUFA ratio, thereby promoting inflammation, since n-3 PUFAs tend to be anti-inflammatory and n-6 PUFAs tend to be pro-inflammatory (reviewed in (Liu et al., 2014)). More indirectly, low n-3 PUFAs disinhibit two inflammatory intermediates, nuclear factor kappa-light-chain-enhancer of activated B cells (NFkB) and 
peroxisome proliferator activated receptors (PPARs). Abnormal monoaminergic neurotransmission and the presence of neuroinflammation are two leading theories of biological pathways to suicide.

\subsection{Effects of PUFAs and cholesterol on lipid rafts}

The plasma membrane was conceptualized by Singer \& Nicolson (Singer and Nicolson, 1972) as a fluid mosaic mixture of lipids and proteins. Alternative paradigms have since been developed, chief among them the lipid raft concept: a glycerophospholipid bilayer containing discrete, spatially and temporally dynamic microdomains (rafts), tightly packed, nano-scale membrane assemblies enriched in cholesterol, sphingolipids, and glycosylphosphatidylinositol (GPI)-anchored proteins (Hancock, 2006). Lipid rafts interact to bring together the components of signaling machinery and influence the trafficking of cellular constituents (Ikonen, 2001, Rajamoorthi et al., 2005).

Due to multiple double bonds, the acyl chains of long-chain PUFAs are extremely flexible and can rapidly change conformational states (Feller and Gawrisch, 2005), resulting in poor packing and higher fluidity, aversive to the tightly-packed, highly ordered cholesterol/ sphingolipid raft domains. In vitro, disruption of lipid rafts is accomplished by reducing cholesterol through techniques such as depletion (Sjogren et al., 2006), sequestration (Schnitzer et al., 1994), or replacement with sterols that do not serve to form ordered domains (Vainio et al., 2006). Studies with in vivo mouse models (Fan et al., 2004, Fan et al., 2003), cell cultures (Grimm et al., 2011, Kim et al., 2008), and model membranes (Kinnun et al., 2018, Williams et al., 2012) also agree that n-3 PUFAs alter lipid raft composition. However, contradictory findings have been reported, as to whether n-3 PUFAs promote the formation of lipid rafts and cause increased membrane order, by herding the cholesterol and sphingolipids into larger domains (Kim, 2008, Kinnun, 2018); or cause decreased membrane order by lowering the levels of cholesterol (Ma et al., 2004) and sphingolipids (Fan, 2004, Fan, 2003) within lipid rafts, shifting the cholesterol to non-raft domains (Grimm, 2011). One study reports that, in contrast to a more global lowering of membrane cholesterol due to pharmacologic depletion, n-3 PUFAs reduce cholesterol only in caveolae (Ma, 2004), and notes that studies in T-cells, which lack caveolae, do not exhibit decreased cholesterol (Fan, 2004, Fan, 2003). Counterintuitively, given the aversion between cholesterol and unsaturated fatty acid chains, several studies in T-cells report that n-3 PUFAs incorporate into the lipid rafts (Fan, 2004, Fan, 2003, Stulnig et al., 2001). Thus prediction about in vivo clinical effects of cholesterol and n-3 PUFAs on lipid raft functioning is necessarily somewhat speculative.

\subsubsection{Effects of PUFAs and cholesterol on lipid rafts: serotonergic neurotransmission.-Membrane lipid rafts are one arena where PUFA balance and} cholesterol reduction intersect and may influence suicide risk by affecting functioning of membrane proteins such as monoaminergic transporters and receptors. Among monoaminergic transporters and receptors that are regulated by lipid rafts, we hypothesize that lipid raft alterations would have the greatest impact on suicide risk via effects on serotonin (5-hydroxytryptamine, 5-HT) transporters (SERT) and receptors, given the associations of the serotonergic pathway with suicidal behavior (reviewed in (Mann, 2003, 
Oquendo, 2014, van Heeringen and Mann, 2014)). Both SERT (Magnani et al., 2004, Samuvel et al., 2005), which regulates synaptic 5-HT concentrations and has effects on the 5-HT receptors, and the 5-HT receptors themselves, most notably the 5-HT $1 \mathrm{~A}$ (Kalipatnapu and Chattopadhyay, 2005, Kobe et al., 2008, Nothdurfter et al., 2011, Renner et al., 2007, Sjogren et al., 2008), 5-HT 2 (Dreja et al., 2002, Mialet-Perez et al., 2012, Sommer et al., 2009), 5-HT $3 \mathrm{~A}$ (Eisensamer et al., 2005, Ilegems et al., 2005, Nothdurfter et al., 2010), and 5-HT $7 \mathrm{~A}$ (Sjogren, 2006, Sjogren and Svenningsson, 2007a, b), localize to lipid rafts.

In vitro studies find that disruption of lipid rafts by cholesterol-interfering agents produces, on average, a 50\% decrease in the transport rate of the SERT and a concurrent reduction in SERT affinity for 5-HT, suggesting that lipid rafts may promote a high-affinity state of SERT (Magnani, 2004, Scanlon et al., 2001). Likewise, reduction of cholesterol reduces agonist and antagonist binding at the 5- $\mathrm{HT}_{1 \mathrm{~A}}$ (Kalipatnapu and Chattopadhyay, 2005, Sjogren, 2008) and 5- $\mathrm{HT}_{7 \mathrm{~A}}$ (Sjogren, 2006) receptors. Interestingly, co-accumulation of certain psychotropic drugs and 5- $\mathrm{HT}_{3 \mathrm{~A}}$ receptors in lipid raft fractions is associated with effects on serotonin-induced cation currents (Eisensamer, 2005), suggesting possible lipid raft-mediated effects of antidepressants and antipsychotics on therapeutic efficacy, including reduction of suicide risk.

Direct evidence of a relationship between PUFAs and serotonergic neurotransmission is limited to rat models, in which n-3 deficiency induces higher basal and lower stimulated levels of serotonin (Kodas et al., 2004) and increased central 5-HT turnover (McNamara et al., 2010a), while high n-6 diets cause alterations in 5- $\mathrm{HT}_{2 \mathrm{~A}}$ and $5-\mathrm{HT}_{2 \mathrm{C}}$ receptors and in 5HT transporter binding (Dubois et al., 2006).

\subsubsection{Effects of PUFAs and cholesterol on lipid rafts: toll-like receptors.-}

Another potential factor in suicide risk involving lipid rafts is the balance of opposing effects of cholesterol and DHA on the dimerization and recruitment of Toll-like receptors (TLR) into lipid rafts. TLRs are pattern recognition receptors that play a key role in recognizing pathogens and triggering immune responses by inducing microglial activation and cytokine production. TLR also activate nuclear factor kappa light chain enhancer of activated B cells (NF- $\kappa \mathrm{B})$, a heterodimeric transcription factor that when activated rapidly migrates into the nucleus of the cell and promotes inflammation through effects on target genes controlling the expression of multiple cytokines, chemokines, adhesion molecules and vascular cell adhesion molecules, and inducible enzymes (Hayden and Ghosh, 2012). Cholesterol and lipid rafts are necessary for TLR activation (Sadikot, 2012). DHA, on the other hand, as one of its anti-inflammatory actions, inhibits the dimerization of TLR, particularly TLR4, and its recruitment into lipid rafts (Wong et al., 2009), and thereby also prevents NF- $\kappa B$ translocation into the nucleus (Chen et al., 2017). Lowering of cholesterol could theoretically disrupt lipid rafts and reduce TLR function and inflammation, but cholesterollowering effects of reducing DHA can have the opposite effect, reversing the DHA inhibition of TLR and thus increasing inflammation. Thus a complex balancing of effects remains to be parsed out. 


\subsection{PUFA interactions with PPARs}

NF- $\kappa$ B is also modulated by the peroxisome proliferator-activated receptors (PPARs) family of nuclear transcription factors, for which EPA, DHA and eicosanoids are natural ligands. Upon activation by EPA or other ligands, PPARs form heterodimers with retinoid X that bind to PPAR-responsive elements in the regulatory region of target genes, reducing the expression of proinflammatory molecules. Thus, in addition to inhibition of NF- $\mathrm{kB}$ via effects on TLR4, n-3 PUFAs downregulate NF- $\mathrm{kB}$ through binding to PPAR $\gamma$ (Rao and Lokesh, 2017). As cholesterol-lowering reduces both DHA effects on TLR and EPA effects on $\operatorname{PPAR} \gamma$, increased inflammation could ensue.

\subsection{PUFA balance and inflammation}

It has long been known that hormones and neurotransmitters which bind to membrane receptors that activate phospholipase $\mathrm{A}_{2}$ release PUFAs from the $s n-2$ position of membrane phospholipids to become substrates for eicosanoid biosynthesis, producing a variety of compounds with pro or anti-inflammatory effects. Most of the mediators formed from n-3 PUFAs have anti-inflammatory effects, while those synthesized n-6 PUFAs are mainly proinflammatory. Very recently, attention also has been focused on anti-inflammatory consequences of n-3 PUFA via effects on macrophages and microglia (Fourrier et al., 2017, Hopperton et al., 2016, Rombaldova et al., 2017, Shen et al., 2017). Elevation of the n-6:n-3 PUFA ratio thus causes a shift toward a pro-inflammatory state, which has emerged as a potentially important factor in the pathophysiology of suicidal behavior. Pro-inflammatory cytokines, particularly IL-6, are associated with suicidal ideation and both nonfatal suicide attempts and suicides (reviewed in (Gananca et al., 2016)).

\subsection{Effect of cholesterol lowering interventions on PUFA levels}

The initial observation of the association between lowering cholesterol serum levels and suicide came from intervention studies (Muldoon, 1990). However, those studies did not measure effects of the interventions on PUFA serum levels. As described below, there is some evidence that cholesterol-lowering interventions, besides modifying cholesterol, affect PUFA serum levels, which thus could perhaps be a mediator of the cholesterol-suicide connection.

2.4.1. Effect of fibrates on PUFAs_Fibrates are synthetic ligands for PPARa receptors, and it is through binding to these nuclear receptors that they act to alter lipid levels. Fibrates primarily reduce triglycerides, have a modest effect on HDL-C levels, and, depending upon the baseline triglyceride levels, may decrease LDL-C levels (in patients without baseline elevation in triglyceride levels) or may substantially increase LDL-C levels (in patients with very high baseline triglyceride levels). (Goldenberg et al., 2008)

Information regarding the effect of fibrates on PUFAs is conflicting, and it seems that the action varies with the type of fibrate. In animal models, bezafibrate, and to a lesser extent gemfibrozil, increase monounsaturated fatty acids (palmitoleic and oleic acids) and decrease PUFAs (mainly linoleic acid has been studied) in microsomal phospholipids (Vazquez et al., 1995). In humans, gemfibrozil produces major modifications in fatty acid composition, decreasing saturated fatty acids and increasing n-6 PUFA (Nyalala et al., 2008). A 
conflicting finding in an animal model (rat heart) is that clofibrate treatment reduces $n-6$ PUFAs (linoleic acid and arachidonic acid) and increases n-3 PUFA (DHA) and increases the unsaturation extent of myocardial fatty acids (Tian et al., 2006). Taken together, these results suggest that fibrates alter PUFAs serum levels, apparently diminishing n-3 PUFAs. However, this effect is not equivalent for all drugs.

2.4.2. Effect of statins on PUFAs-Statins were originally believed to be effective in treating cardiovascular illness by inhibiting the synthesis of mevalonate, acting on HMGCoA reductase, and thereby reducing the serum levels of LDL and increasing HDL (Stancu and Sima, 2001). However, statins have pleiotropic biochemical effects beyond the inhibition of cholesterol synthesis and some of these effects modify PUFA levels, altering the balance of $n-3$ to $n-6$ PUFAs, apparently by affecting desaturation and elongation (Rise et al., 2001).

In cultured monocytic cells, simvastatin activates the formation of AA from LA, mainly acting at the delta 5 desaturation steps, and increases the mRNA levels of delta 5 desaturase (Rise et al., 2002). In patients with dyslipidemia, rosuvastatin and pitavastatin decrease serum DHA and increase the AA/DHA ratio (Nozue and Michishita, 2015); similarly, pravastatin and simvastatin treatment increase the AA/EPA ratio (Harris et al., 2004, Nakamura et al., 1998) and tend to increase the AA/DHA ratio (Harris, 2004).

Taken together, this information suggests that statins affect PUFA synthesis, particularly increasing serum concentration of AA or the concentration of AA relative to n-3 PUFAs (DHA and EPA), although as for fibrates, individual statin drugs may have differing effects.

2.4.3. Comparisons of fibrate and statin effects on PUFAs-Several studies have simultaneously assessed the effects of fibrates and statins. In one study of plasma lipids of hyperlipidemic patients, elevation of AA occurred in those treated with statins but not those treated with fibrates; AA elevation was associated with concomitant selective escalation of product/precursor ratios for delta 5 desaturation in hypercholesterolemic patients (Rise, 2001). The opposite result was seen in another study which compared the magnitude of effects of atorvastatin, simvastatin and gemfibrozil (Nyalala, 2008), on fatty acid composition in human plasma and red blood cell membranes; they found that n-6 PUFA levels were increased with both treatments, but the effects of gemfibrozil were significant while the effects of statins were not. Finally, a study comparing patients treated with fenofibrate vs. simvastatin for 3 months found significant increases in both groups for n-6 PUFAs, including AA and other intermediate n- 6 species, and a concomitant decrease in the n-6 precursor, LA, but observed a decrease in two major n-3 PUFAs (ALA and DHA) in fibrates only (de Lorgeril, 2005). At this time, there is no resolution of these contradictory findings. Differentially stronger effects of fibrates on PUFA balance could, however, pertain to why the most recent meta-analysis (Muldoon, 2001) found a trend $(p=0.06)$ in increased risk of suicide/violent death/accidents with respect to fibrates but no increase with respect to statins.

2.4.4. Effect of proprotein convertase subtilisin-kexin type 9 serine protease (PSCK9) inhibitors-New, highly effective cholesterol lowering drugs, PSCK9 inhibitors, 
have not been associated with suicidal behavior, according to a meta-analysis of 13,083 patients in 17 clinical trials (Lipinski et al., 2016); however, neurocognitive side effects (amnesia, alterations in memory and confusional state) were reported. Taking into account that there are still few studies published and with short-term follow-ups, potential effects of PSCK9 inhibitors on suicidal behavior should not be ruled out. In a cardiovascular context, effects of dietary n-3 PUFAs may be mediated by direct effects of DHA on PCSK9. (Graversen et al., 2016, Rodriguez-Perez et al., 2016, Yu et al., 2017)

2.4.5. Effect of cholesterol-lowering diets on PUFA levels-In the meta-analyses of Muldoon et al. (Muldoon, 1990, Muldoon, 2001), subjects undergoing dietary interventions ( $\mathrm{Z}$-score $=1.77, p=0.08$ (Muldoon, 1990)) or dietary interventions lumped with non-statin treatment $(\mathrm{OR}=1.32 ; \mathrm{CI}=1.32-0.98 ; p=0.06$ (Muldoon, 2001)) showed a trend toward increased death from non-illness mortality. Details of the dietary interventions were not available.

\section{Discussion}

We have expanded upon the previous work of Hibbeln and Salem, who postulated that, "fatty acids may be a critical variable which links cholesterol lowering therapies to suicide or depression," (Hibbeln and Salem, 1996). Our theoretical model explicates several possible pathways whereby cholesterol-lowering treatments can affect PUFAs and lipid rafts, leading to alterations in serotonergic neurotransmission and/or inflammation and thereby increase suicide risk.

Complexities in the proposed model center around how effects of cholesterol lowering and changes in PUFA balance affect lipid rafts, which have some of the qualities of a "black box". We know that aversive relationships between highly unsaturated fatty acids and large cholesterol and sphingolipid molecules have biophysical effects on lipid raft structure with functional consequences. However, lipid rafts pose extreme technical challenges for clinical study, as rafts are dynamic systems that are nanoscalar, both temporally and molecularly. Thus to date, current knowledge relies on studies in model membranes, cell culture, and some in vivo rodent studies.

Another complexity is that although statins have been shown to decrease cholesterol and increase n-6 PUFA blood levels with respect to n-3 levels, a meta-analysis performed in 2001 found that in contrast to fibrates and diet, statins showed not only no significant increase in deaths by accidents, violence, and suicide, but rather a tendency to reduce nonillness mortality (Muldoon, 2001). In concordance with our explanatory model, this may be due to a greater impact of fibrates compared with statins on PUFA status (de Lorgeril, 2005, Nyalala, 2008). Additionally, statin mechanisms of action other than lipid reduction have been recognized (Tousoulis et al., 2014), including anti-inflammatory properties. Metaanalyses suggest that statins' benefits for atherosclerosis are primarily associated with their anti-inflammatory actions (An et al., 2017, Li et al., 2018), particularly in the case of lipophilic statins (Bonsu et al., 2015), which also comports with the premise in our model that lipid effects on suicide risk may relate to their effects on inflammatory state. Thus, statins' anti-inflammatory properties may actually mitigate suicide risk. 
Another relevant question is whether statins have any effects on aggression, which may be a psychiatric mediator or moderator of suicidal behavior. One randomized clinical trial (Golomb et al., 2015) has addressed this question, finding age and sex effects of statin treatment: aggression was decreased in men, particularly men with low baseline aggression, after outliers were removed; these outliers included men in whom statins induced markedly increased aggression, and this was found to be associated with statin-induced side effect of sleep problems. Moreover, aggression was increased in postmenopausal women. The same research group also reported on a case series of 12 patients who took statins and self-referred for assessment of subsequent mood or behavior changes including irritability, depressed mood, and suicidal ideation, suicide attempts and suicide completion (Cham et al., 2016). From a precision medicine standpoint, these findings suggest that although in the aggregate statins tend to decrease suicide risk, certain individuals may have a biological or behavioral phenotype that would confer vulnerability to statin-induced aggression, depression and suicide risk.

We have described mechanisms through which cholesterol-lowering drugs may increase the proportion of n-6 PUFAs. Dietary interventions also showed a trend toward increased suicide mortality (Muldoon, 1990, Muldoon, 2001). How does this relate to the hypothesis that cholesterol relationships to suicide risk are confounded by the underlying PUFA balance? The specifics of the dietary interventions included in these meta-analyses are not readily available for examination. However, U.S. dietary guidelines (Office of Disease Prevention and Healthy Promotion, 2017) on lipid consumption for 1990 stated, "Choose liquid vegetable oils most often because they are lower in saturated fat" and similarly for 2000, "Choose vegetable oils rather than solid fats (meat and dairy fats, shortening)." Although the Mediterranean diet had been proposed previously (Keys and Keys, 1975), possible benefits of using olive oil and n-3-rich oils were not widely recognized during that time period. Assuming that dietary interventions for improved heart health adhered to the nutritional wisdom of the time, then it is likely that study participants were instructed to choose vegetable oils over animal fats. Analysis of n-3 and n-6 PUFA concentrations in a sampling of 14 vegetable oils (olive oil and canola oil were not included) found the average amount of n-6 PUFAs to be $43.4 \pm 24.7 \%$ of total fatty acid methyl esters while n-3 PUFAs made up only $0.47 \pm 0.53 \%$ (Orsavova et al., 2015). Thus, comporting with our model, increasing intake of vegetable oils would be expected to have reduced saturated fats but increased intake of n-6 PUFAs.

Like any theoretical schema, our proposed model is an oversimplification. As yet understudied is the extent to which the two pathways we have identified, serotonergic neurotransmission and inflammation, may be related and create a final common pathway to suicide risk. Along these lines, there are reports that serotonin reuptake inhibitors inhibit activation of microglia (Su et al., 2015) and that an abnormal astrocyte-microglia balance is associated with impaired serotonergic functioning (Müller and Schwarz, 2007).

To better understand treatment effects of PUFAs, future studies should assess diet, taking into account not just concentrations of PUFAs but also percentage composition and the relative effects across the lipidome on different lipid classes (phospholipids, cholesteryl esters, unesterified fraction). Additional important factors to be studied include lipid- 
associated genetic variants and epigenetic marks that modulate the effects of lipid status on suicide risk.

\subsection{Limitations}

In reviewing the literature pertinent to cholesterol, PUFAs and suicide risk, we are hampered by the lack of a) clinical trials with suicidal behavior as outcome measures and b) studies that fully characterize the lipidome. Therefore, although evidence supports each step in our hypothesized model (Fig 1), and the model possesses face validity, in order to establish mechanisms of action as postulated in our model, mediation analyses would need to be undertaken, which require large sample sizes.

\subsection{Conclusions}

Based on a survey of relevant scientific literature, we propose links between low cholesterol, elevated n-6 to n-3 PUFAs, lower 5-HT neurotransmission, inflammation, and suicide risk. Effects of cholesterol-PUFA balance on lipid rafts are a mechanistic linchpin deserving of additional study in this regard. If our model is correct, the use of cholesterol-lowering treatments has implications for personalized medicine as well as an impact on public health. There could be preventative value, with respect to suicide, in administering n-3 PUFA supplements to cardiac patients for whom lower cholesterol is medically important and who have or develop psychiatric vulnerabilities.

\section{Abbreviations:}

DHA docosahexaenoic acid

EPA eicosapentaenoic acid

PPARs peroxisome proliferator-activated receptors

TLR Toll-like receptor

NF-KB nuclear factor kappa-light-chain-enhancer of activated B cells

5-HT 5-hydroxytryptamine (serotonin)

PUFAs polyunsaturated fatty acids.

\section{References}

Adams P, Lawson S, Sanigorski A, Sinclair A, 1996 Arachidonic acid to eicosapentaenoic acid ratio in blood correlates positively with clinical symptoms of depression. Lipids. 31, S157-61. [PubMed: 8729112]

Amin AA, Menon RA, Reid KJ, Harris WS, Spertus JA, 2008 Acute coronary syndrome patients with depression have low blood cell membrane omega-3 fatty acid levels. Psychosom. Med. 70, 856-62.

An J, Shi F, Liu S, Ma J, Ma Q, 2017 Preoperative statins as modifiers of cardiac and inflammatory outcomes following coronary artery bypass graft surgery: a meta-analysis. Interactive cardiovascular and thoracic surgery. 25, 958-65. [PubMed: 29049804] 
Appleton KM, Hayward RC, Gunnell D, Peters TJ, Rogers PJ, Kessler D, et al., 2006 Effects of n-3 long-chain polyunsaturated fatty acids on depressed mood: systematic review of published trials. Am. J. Clin. Nutr 84, 1308-16. [PubMed: 17158410]

Appleton KM, Rogers PJ, Ness AR, 2010 Updated systematic review and meta-analysis of the effects of n-3 long-chain polyunsaturated fatty acids on depressed mood. Am. J. Clin. Nutr 91, 757-70. [PubMed: 20130098]

Appleton KM, Sallis HM, Perry R, Ness AR, Churchill R, 2015 Omega-3 fatty acids for depression in adults. Cochrane Database Syst Rev. 11, CD004692.

Beier AM, Lauritzen L, Galfalvy HC, Cooper TB, Oquendo MA, Grunebaum MF, et al., 2014 Low plasma eicosapentaenoic acid levels are associated with elevated trait aggression and impulsivity in major depressive disorder with a history of comorbid substance use disorder. J. Psychiatr. Res 57, 133-40. [PubMed: 25017608]

Bloch MH, Hannestad J, 2012 Omega-3 fatty acids for the treatment of depression: systematic review and meta-analysis. Mol. Psychiatry 17, 1272-82. [PubMed: 21931319]

Bonsu KO, Reidpath DD, Kadirvelu A, 2015 Effects of Statin Treatment on Inflammation and Cardiac Function in Heart Failure: An Adjusted Indirect Comparison Meta-Analysis of Randomized Trials. Cardiovascular therapeutics. 33, 338-46. [PubMed: 26280110]

Buydens-Branchey L, Branchey M, McMakin DL, Hibbeln JR, 2003 Polyunsaturated fatty acid status and aggression in cocaine addicts. Drug Alcohol Depend. 71, 319-23. [PubMed: 12957349]

Cham S, Koslik HJ, Golomb BA, 2016 Mood, Personality, and Behavior Changes During Treatment with Statins: A Case Series. Drug safety - case reports. 3, 1. [PubMed: 27747681]

Chen X, Wu S, Chen C, Xie B, Fang Z, Hu W, et al., 2017 Omega-3 polyunsaturated fatty acid supplementation attenuates microglial-induced inflammation by inhibiting the HMGB1/TLR4/NFkappaB pathway following experimental traumatic brain injury. J Neuroinflammation. 14, 143. [PubMed: 28738820]

Chu J, Robinett EN, Ma JKL, Shadish KY, Goldblum P, Bongar B, 2018 Cultural versus classic risk and protective factors for suicide. Death Stud.

Conklin SM, Manuck SB, Yao JK, Flory JD, Hibbeln JR, Muldoon MF, 2007 High omega-6 and low omega-3 fatty acids are associated with depressive symptoms and neuroticism. Psychosom. Med 69, 932-4. [PubMed: 17991818]

de Lorgeril M, Salen P, Guiraud A, Zeghichi S, Boucher F, de Leiris J, 2005 Lipid-lowering drugs and essential omega- 6 and omega-3 fatty acids in patients with coronary heart disease. Nutr Metab Cardiovasc Dis. 15, 36-41. [PubMed: 15871849]

Dietschy JM, Turley SD, 2001 Cholesterol metabolism in the brain. Curr. Opin. Lipidol 12, 105-12. [PubMed: 11264981]

Dinan T, Siggins L, Scully P, O'Brien S, Ross P, Stanton C, 2009 Investigating the inflammatory phenotype of major depression: focus on cytokines and polyunsaturated fatty acids. J. Psychiatr. Res 43, 471-6. [PubMed: 18640689]

Dreja K, Voldstedlund M, Vinten J, Tranum-Jensen J, Hellstrand P, Sward K, 2002 Cholesterol depletion disrupts caveolae and differentially impairs agonist-induced arterial contraction. Arterioscler. Thromb. Vasc. Biol 22, 1267-72. [PubMed: 12171786]

Dubois T, Deng C, Bell W, Huang X, 2006 Fatty acids differentially affect serotonin receptor and transporter binding in the rat brain. Neuroscience. 139, 1397-403. [PubMed: 16600514]

Edwards R, Peet M, Shay J, Horrobin D, 1998 Omega-3 polyunsaturated fatty acid levels in the diet and in red blood cell membranes of depressed patients. J. Affect. Disord 48, 149-55. [PubMed: 9543204]

Eisensamer B, Uhr M, Meyr S, Gimpl G, Deiml T, Rammes G, et al., 2005 Antidepressants and antipsychotic drugs colocalize with 5-HT3 receptors in raft-like domains. The Journal of neuroscience : the official journal of the Society for Neuroscience. 25, 10198-206. [PubMed: 16267227]

Fan YY, Ly LH, Barhoumi R, McMurray DN, Chapkin RS, 2004 Dietary docosahexaenoic acid suppresses $\mathrm{T}$ cell protein kinase $\mathrm{C}$ theta lipid raft recruitment and IL-2 production. J. Immunol 173, 6151-60. [PubMed: 15528352] 
Fan YY, McMurray DN, Ly LH, Chapkin RS, 2003 Dietary (n-3) polyunsaturated fatty acids remodel mouse T-cell lipid rafts. J. Nutr 133, 1913-20. [PubMed: 12771339]

Féart C, Peuchant E, Letenneur L, Samieri C, Montagnier D, Fourrier-Reglat A, et al., 2008 Plasma eicosapentaenoic acid is inversely associated with severity of depressive symptomatology in the elderly: data from the Bordeaux sample of the Three-City Study. Am. J. Clin. Nutr 87, 1156-62. [PubMed: 18469234]

Feller SE, Gawrisch K, 2005 Properties of docosahexaenoic-acid-containing lipids and their influence on the function of rhodopsin. Curr. Opin. Struct. Biol 15, 416-22. [PubMed: 16039844]

Fourrier C, Remus-Borel J, Greenhalgh AD, Guichardant M, Bernoud-Hubac N, Lagarde M, et al., 2017 Docosahexaenoic acid-containing choline phospholipid modulates LPS-induced neuroinflammation in vivo and in microglia in vitro. J Neuroinflammation. 14, 170. [PubMed: 28838312]

Frasure-Smith N, Lesperance F, Julien P, 2004 Major depression is associated with lower omega-3 fatty acid levels in patients with recent acute coronary syndromes. Biol. Psychiatry 55, 891-6. [PubMed: 15110732]

Gananca L, Oquendo MA, Tyrka AR, Cisneros-Trujillo S, Mann JJ, Sublette ME, 2016 The role of cytokines in the pathophysiology of suicidal behavior. Psychoneuroendocrinology. 63, 296-310. [PubMed: 26546783]

Garland MR, Hallahan B, McNamara M, Carney PA, Grimes H, Hibbeln JR, et al., 2007 Lipids and essential fatty acids in patients presenting with self-harm. Br. J. Psychiatry 190, 112-7. [PubMed: 17267926]

Ghaemi SN, Shields GS, Hegarty JD, Goodwin FK, 2000 Cholesterol levels in mood disorders: high or low? Bipolar Disord. 2, 60-4. [PubMed: 11254022]

Goldenberg I, Benderly M, Goldbourt U, 2008 Update on the use of fibrates: focus on bezafibrate. Vascular health and risk management. 4, 131-41. [PubMed: 18629356]

Golomb BA, Dimsdale JE, Koslik HJ, Evans MA, Lu X, Rossi S, et al., 2015 Statin Effects on Aggression: Results from the UCSD Statin Study, a Randomized Control Trial. PLoS One. 10, e0124451. [PubMed: 26132393]

Graversen CB, Lundbye-Christensen S, Thomsen B, Christensen JH, Schmidt EB, 2016 Marine n-3 polyunsaturated fatty acids lower plasma proprotein convertase subtilisin kexin type 9 levels in pre- and postmenopausal women: A randomised study. Vascular pharmacology. 76, 37-41. [PubMed: 26143741]

Grimm MO, Kuchenbecker J, Grosgen S, Burg VK, Hundsdörfer B, Rothhaar TL, et al., 2011 Docosahexaenoic acid reduces amyloid beta production via multiple pleiotropic mechanisms. J. Biol. Chem 286, 14028-39. [PubMed: 21324907]

Grosso G, Pajak A, Marventano S, Castellano S, Galvano F, Bucolo C, et al., 2014 Role of omega-3 fatty acids in the treatment of depressive disorders: a comprehensive meta-analysis of randomized clinical trials. PLoS One. 9, e96905. [PubMed: 24805797]

Hancock JF, 2006 Lipid rafts: contentious only from simplistic standpoints. Nature reviews. Molecular cell biology. 7, 456-62. [PubMed: 16625153]

Harris JI, Hibbeln JR, Mackey RH, Muldoon MF, 2004 Statin treatment alters serum n-3 and n-6 fatty acids in hypercholesterolemic patients. PLEFA. 71, 263-9.

Hayden MS, Ghosh S, 2012 NF-kappaB, the first quarter-century: remarkable progress and outstanding questions. Genes Dev. 26, 203-34. [PubMed: 22302935]

Hibbeln JR, Salem N, Jr., 1995 Dietary polyunsaturated fatty acids and depression: when cholesterol does not satisfy. Am. J. Clin. Nutr 62, 1-9. [PubMed: 7598049]

Hibbeln JR, Salem N, Jr., 1996 Risks of cholesterol-lowering therapies. Biol. Psychiatry 40, 686-7. [PubMed: 8886308]

Hopperton KE, Trepanier MO, Giuliano V, Bazinet RP, 2016 Brain omega-3 polyunsaturated fatty acids modulate microglia cell number and morphology in response to intracerebroventricular amyloid-beta 1-40 in mice. J Neuroinflammation. 13, 257. [PubMed: 27688126]

Huan M, Hamazaki K, Sun Y, Itomura M, Liu H, Kang W, et al., 2004 Suicide attempt and n-3 fatty acid levels in red blood cells: a case control study in China. Biol. Psychiatry 56, 490-6. [PubMed: 15450784] 
Ikonen E, 2001 Roles of lipid rafts in membrane transport. Curr. Opin. Cell Biols 13, 470-7. [PubMed: $11454454]$

Ilegems E, Pick H, Deluz C, Kellenberger S, Vogel H, 2005 Ligand binding transmits conformational changes across the membrane-spanning region to the intracellular side of the 5-HT3 serotonin receptor. Chembiochem. 6, 2180-5. [PubMed: 16254942]

Jump DB, 2002 The biochemistry of n-3 polyunsaturated fatty acids. J. Biol. Chem 277, 8755-8. [PubMed: 11748246]

Kalipatnapu S, Chattopadhyay A, 2005 Membrane organization of the human serotonin(1A) receptor monitored by detergent insolubility using GFP fluorescence. Mol. Membr. Biol 22, 539-47. [PubMed: 16373325]

Kaplan JR, Shively CA, Fontenot MB, Morgan TM, Howell SM, Manuck SB, et al., 1994 Demonstration of an association among dietary cholesterol, central serotonergic activity, and social behavior in monkeys. Psychosom. Med 56, 479-84. [PubMed: 7532867]

Keys AB, Keys M How to eat well and stay well the Mediterranean way. 1st ed Garden City, N.Y.,: Doubleday; 1975.

Kim W, Fan YY, Barhoumi R, Smith R, McMurray DN, Chapkin RS, 2008 n-3 polyunsaturated fatty acids suppress the localization and activation of signaling proteins at the immunological synapse in murine CD4+ T cells by affecting lipid raft formation. J. Immunol 181, 6236-43. [PubMed: 18941214]

Kinnun JJ, Bittman R, Shaikh SR, Wassall SR, 2018 DHA Modifies the Size and Composition of Raftlike Domains: A Solid-State (2)H NMR Study. Biophys. J 114, 380-91. [PubMed: 29401435]

Kobe F, Renner U, Woehler A, Wlodarczyk J, Papusheva E, Bao G, et al., 2008 Stimulation- and palmitoylation-dependent changes in oligomeric conformation of serotonin 5-HT1A receptors. Biochim. Biophys. Acta 1783, 1503-16. [PubMed: 18381076]

Kodas E, Galineau L, Bodard S, Vancassel S, Guilloteau D, Besnard J, et al., 2004 Serotoninergic neurotransmission is affected by n-3 polyunsaturated fatty acids in the rat. J. Neurochem $89,695-$ 702. [PubMed: 15086526]

Lewis MD, Hibbeln JR, Johnson JE, Lin YH, Hyun DY, Loewke JD, 2011 Suicide deaths of activeduty US military and omega-3 fatty-acid status: a case-control comparison. J. Clin. Psychiatry

Li GM, Zhao J, Li B, Zhang XF, Ma JX, Ma XL, et al. 2018 The anti-inflammatory effects of statins on patients with rheumatoid arthritis: A systemic review and meta-analysis of 15 randomized controlled trials. Autoimmunity reviews.

Lin PY, Huang SY, Su KP, 2010 A Meta-Analytic Review of Polyunsaturated Fatty Acid Compositions in Patients with Depression. Biol. Psychiatry 68, 140-7. [PubMed: 20452573]

Lipinski MJ, Benedetto U, Escarcega RO, Biondi-Zoccai G, Lhermusier T, Baker NC, et al., 2016 The impact of proprotein convertase subtilisin-kexin type 9 serine protease inhibitors on lipid levels and outcomes in patients with primary hypercholesterolaemia: a network meta-analysis. Eur. Heart J 37, 536-45. [PubMed: 26578202]

Liu JJ, Green P, John Mann J, Rapoport SI, Sublette ME, 2014 Pathways of polyunsaturated fatty acid utilization: Implications for brain function in neuropsychiatric health and disease. Brain Res.

Ma DW, Seo J, Davidson LA, Callaway ES, Fan YY, Lupton JR, et al., 2004 n-3 PUFA alter caveolae lipid composition and resident protein localization in mouse colon. FASEB J. 18, 1040-2. [PubMed: 15084525]

Maes M, Christophe A, Delanghe J, Altamura C, Neels H, Meltzer HY, 1999 Lowered omega3 polyunsaturated fatty acids in serum phospholipids and cholesteryl esters of depressed patients. Psychiatry Res. 85, 275-91. [PubMed: 10333380]

Magnani F, Tate CG, Wynne S, Williams C, Haase J, 2004 Partitioning of the serotonin transporter into lipid microdomains modulates transport of serotonin. J. Biol. Chem. 279, 38770-8. [PubMed: 15226315]

Mamalakis G, 2002 Depression and adipose essential polyunsaturated fatty acids. PLEFA. 67, 311-8.

Mamalakis G, Kalogeropoulos N, Andrikopoulos N, Hatzis C, Kromhout D, Moschandreas J, et al., 2006a Depression and long chain n-3 fatty acids in adipose tissue in adults from Crete. Eur. J. Clin. Nutr 60, 882-8. [PubMed: 16465199] 
Mamalakis G, Kiriakakis M, Tsibinos G, Hatzis C, Flouri S, Mantzoros C, et al., 2006b Depression and serum adiponectin and adipose omega- 3 and omega- 6 fatty acids in adolescents. Pharmacol. Biochem. Behav 85, 474-9. [PubMed: 17126386]

Mann JJ, 2003 Neurobiology of suicidal behaviour. Nat Rev Neurosci. 4, 819-28. [PubMed: 14523381]

Mann JJ, Waternaux C, Haas GL, Malone KM, 1999 Toward a clinical model of suicidal behavior in psychiatric patients. Am. J. Psychiatry 156, 181-9. [PubMed: 9989552]

Martins JG, 2009 EPA but not DHA appears to be responsible for the efficacy of omega-3 long chain polyunsaturated fatty acid supplementation in depression: evidence from a meta-analysis of randomized controlled trials. J. Am. Coll. Nutr 28, 525-42. [PubMed: 20439549]

Martins JG, Bentsen H, Puri BK, 2012 Eicosapentaenoic acid appears to be the key omega-3 fatty acid component associated with efficacy in major depressive disorder: a critique of Bloch and Hannestad and updated meta-analysis. Mol. Psychiatry 17, 1144-9. [PubMed: 22488258]

McNamara RK, Jandacek R, Rider T, Tso P, Cole-Strauss A, Lipton JW, 2010a Omega-3 fatty acid deficiency increases constitutive pro-inflammatory cytokine production in rats: relationship with central serotonin turnover. PLEFA. 83, 185-91.

McNamara RK, Jandacek R, Rider T, Tso P, Dwivedi Y, Pandey GN, 2010b Selective deficits in erythrocyte docosahexaenoic acid composition in adult patients with bipolar disorder and major depressive disorder. J. Affect. Disord 126, 303-11. [PubMed: 20413162]

Meyer BJ, Mann NJ, Lewis JL, Milligan GC, Sinclair AJ, Howe PR, 2003 Dietary intakes and food sources of omega-6 and omega-3 polyunsaturated fatty acids. Lipids. 38, 391-8. [PubMed: 12848284]

Mialet-Perez J, D'Angelo R, Villeneuve C, Ordener C, Negre-Salvayre A, Parini A, et al., 2012 Serotonin 5-HT2A receptor-mediated hypertrophy is negatively regulated by caveolin-3 in cardiomyoblasts and neonatal cardiomyocytes. J. Mol. Cell. Cardiol 52, 502-10. [PubMed: 21820441]

Mocking RJ, Harmsen I, Assies J, Koeter MW, Ruhe HG, Schene AH, 2016 Meta-analysis and metaregression of omega-3 polyunsaturated fatty acid supplementation for major depressive disorder. Translational psychiatry. 6, e756. [PubMed: 26978738]

Muldoon MF, Manuck SB, Matthews KA, 1990 Lowering cholesterol concentrations and mortality: a quantitative review of primary prevention trials. BMJ. 301, 309-14. [PubMed: 2144195]

Muldoon MF, Manuck SB, Mendelsohn AB, Kaplan JR, Belle SH, 2001 Cholesterol reduction and non-illness mortality: meta-analysis of randomised clinical trials. BMJ. 322, 11-5. [PubMed: 11141142]

Müller N, Schwarz MJ, 2007 The immune-mediated alteration of serotonin and glutamate: towards an integrated view of depression. Mol. Psychiatry 12, 988-1000. [PubMed: 17457312]

Nakamura N, Hamazaki T, Jokaji H, Minami S, Kobayashi M, 1998 Effect of HMG-CoA reductase inhibitors on plasma polyunsaturated fatty acid concentrations in patients with hyperlipidemia. Int. J. Clin. Lab. Res 28, 192-5. [PubMed: 9801932]

Nothdurfter C, Tanasic S, Di Benedetto B, Rammes G, Wagner EM, Kirmeier T, et al., 2010 Impact of lipid raft integrity on 5-HT3 receptor function and its modulation by antidepressants. Neuropsychopharmacology. 35, 1510-9. [PubMed: 20200506]

Nothdurfter C, Tanasic S, Rammes G, Rupprecht R, 2011 Modulation of ligand-gated ion channels as a novel pharmacological principle. Pharmacopsychiatry. 44 Suppl 1, S27-34. [PubMed: 21544743]

Nozue T, Michishita I, 2015 Statin treatment alters serum n-3 to n-6 polyunsaturated fatty acids ratio in patients with dyslipidemia. Lipids Health Dis. 14, 67. [PubMed: 26149129]

Nyalala JO, Wang J, Dang A, Faas FH, Smith WG, 2008 Hypertriglyceridemia and hypercholesterolemia: effects of drug treatment on fatty acid composition of plasma lipids and membranes. PLEFA. 78, 271-80.

Office of Disease Prevention and Healthy Promotion. Dietary Guidelines. 2017.

Oquendo MA, Sullivan GM, Sudol K, Baca-Garcia E, Stanley BH, Sublette ME, et al., 2014 Toward a biosignature for suicide. Am. J. Psychiatry. 171, 1259-77. [PubMed: 25263730]

Orsavova J, Misurcova L, Ambrozova JV, Vicha R, Mlcek J, 2015 Fatty Acids Composition of Vegetable Oils and Its Contribution to Dietary Energy Intake and Dependence of Cardiovascular 
Mortality on Dietary Intake of Fatty Acids. International journal of molecular sciences. 16, 1287190. [PubMed: 26057750]

Papandreou C, Schiza SE, Tsibinos G, Mermigkis C, Hatzis CM, Kafatos AG, et al., 2011 Gluteal adipose-tissue polyunsaturated fatty-acids profiles and depressive symptoms in obese adults with obstructive sleep apnea hypopnea syndrome: a cross-sectional study. Pharmacol. Biochem. Behav 98, 316-9. [PubMed: 21281660]

Peet M, Murphy B, Shay J, Horrobin D, 1998 Depletion of omega-3 fatty acid levels in red blood cell membranes of depressive patients. Biol. Psychiatry 43, 315-9. [PubMed: 9513745]

Rajamoorthi K, Petrache HI, McIntosh TJ, Brown MF, 2005 Packing and viscoelasticity of polyunsaturated omega-3 and omega-6 lipid bilayers as seen by (2)H NMR and X-ray diffraction. J. Am. Chem. Soc 127, 1576-88. [PubMed: 15686391]

Rao YP, Lokesh BR, 2017 Down-regulation of NF-kappaB expression by n-3 fatty acid-rich linseed oil is modulated by PPARgamma activation, eicosanoid cascade and secretion of cytokines by macrophages in rats fed partially hydrogenated vegetable fat. Eur. J. Nutr 56, 1135-47. [PubMed: 26830417]

Rees AM, Austin MP, Owen C, Parker G, 2009 Omega-3 deficiency associated with perinatal depression: case control study. Psychiatry Res. 166, 254-9. [PubMed: 19268372]

Renner U, Glebov K, Lang T, Papusheva E, Balakrishnan S, Keller B, et al., 2007 Localization of the mouse 5-hydroxytryptamine $(1 \mathrm{~A})$ receptor in lipid microdomains depends on its palmitoylation and is involved in receptor-mediated signaling. Mol. Pharmacol 72, 502-13. [PubMed: 17540717]

Riemer S, Maes M, Christophe A, Rief W, 2010 Lowered omega-3 PUFAs are related to major depression, but not to somatization syndrome. J. Affect. Disord 123, 173-80. [PubMed: 19720401]

Rise P, Marangoni F, Galli C, 2002 Regulation of PUFA metabolism: pharmacological and toxicological aspects. PLEFA. 67, 85-9.

Rise P, Pazzucconi F, Sirtori CR, Galli C, 2001 Statins enhance arachidonic acid synthesis in hypercholesterolemic patients. Nutr Metab Cardiovasc Dis. 11, 88-94. [PubMed: 11434193]

Rodriguez-Perez C, Ramprasath VR, Pu S, Sabra A, Quirantes-Pine R, Segura-Carretero A, et al., 2016 Docosahexaenoic Acid Attenuates Cardiovascular Risk Factors via a Decline in Proprotein Convertase Subtilisin/Kexin Type 9 (PCSK9) Plasma Levels. Lipids. 51, 75-83. [PubMed: 26620373]

Rombaldova M, Janovska P, Kopecky J, Kuda O, 2017 Omega-3 fatty acids promote fatty acid utilization and production of pro-resolving lipid mediators in alternatively activated adipose tissue macrophages. Biochem. Biophys. Res. Commun 490, 1080-5. [PubMed: 28668396]

Sadikot R The Role of Cholesterol and Lipid Rafts in Regulation of TLR Receptors In: Levitan I, Barrantes FJ, editors. Cholesterol Regulation of Ion Channels and Receptors. Hoboken, NJ: John Wiley \& Sons; 2012.

Samuvel DJ, Jayanthi LD, Bhat NR, Ramamoorthy S, 2005 A role for p38 mitogen-activated protein kinase in the regulation of the serotonin transporter: evidence for distinct cellular mechanisms involved in transporter surface expression. J. Neurosci 25, 29-41. [PubMed: 15634764]

Sarri KO, Linardakis M, Tzanakis N, Kafatos AG, 2008 Adipose DHA inversely associated with depression as measured by the Beck Depression Inventory. PLEFA. 78, 117-22.

Scanlon SM, Williams DC, Schloss P, 2001 Membrane cholesterol modulates serotonin transporter activity. Biochemistry (Mosc). 40, 10507-13.

Schins A, Crijns HJ, Brummer RJ, Wichers M, Lousberg R, Celis S, et al., 2007 Altered omega-3 polyunsaturated fatty acid status in depressed post-myocardial infarction patients. Acta Psychiatr. Scand 115, 35-40. [PubMed: 17201864]

Schnitzer JE, Oh P, Pinney E, Allard J, 1994 Filipin-sensitive caveolae-mediated transport in endothelium: reduced transcytosis, scavenger endocytosis, and capillary permeability of select macromolecules. J. Cell Biol. 127, 1217-32. [PubMed: 7525606]

Shen L, Yang Y, Ou T, Key CC, Tong SH, Sequeira RC, et al., 2017 Dietary PUFAs attenuate NLRP3 inflammasome activation via enhancing macrophage autophagy. J. Lipid Res 58, 1808-21. [PubMed: 28729463]

Simopoulos AP, 2011 Evolutionary aspects of diet: the omega-6/omega-3 ratio and the brain. Mol. Neurobiol 44, 203-15. [PubMed: 21279554] 
Singer SJ, Nicolson GL, 1972 The fluid mosaic model of the structure of cell membranes. Science. 175, 720-31. [PubMed: 4333397]

Sjogren B, Csoregh L, Svenningsson P, 2008 Cholesterol reduction attenuates 5-HT1A receptormediated signaling in human primary neuronal cultures. Naunyn. Schmiedebergs Arch. Pharmacol 378, 441-6. [PubMed: 18607571]

Sjogren B, Hamblin MW, Svenningsson P, 2006 Cholesterol depletion reduces serotonin binding and signaling via human 5-HT(7(a)) receptors. Eur. J. Pharmacol 552, 1-10. [PubMed: 17064686]

Sjogren B, Svenningsson P, 2007a Caveolin-1 affects serotonin binding and cell surface levels of human 5-HT7(a) receptors. FEBS Lett. 581, 5115-21. [PubMed: 17936759]

Sjogren B, Svenningsson P, 2007b Depletion of the lipid raft constituents, sphingomyelin and ganglioside, decreases serotonin binding at human 5-HT7(a) receptors in HeLa cells. Acta Physiol (Oxf). 190, 47-53. [PubMed: 17428232]

Sommer B, Montano LM, Carbajal V, Flores-Soto E, Ortega A, Ramirez-Oseguera R, et al., 2009 Extraction of membrane cholesterol disrupts caveolae and impairs serotonergic (5-HT2A) and histaminergic (H1) responses in bovine airway smooth muscle: role of Rho-kinase. Can. J. Physiol. Pharmacol 87, 180-95. [PubMed: 19295659]

Spector AA, 1999 Essentiality of fatty acids. Lipids. 34 Suppl, S1-3. [PubMed: 10419080]

Stancu C, Sima A, 2001 Statins: mechanism of action and effects. Journal of cellular and molecular medicine. 5, 378-87. [PubMed: 12067471]

Stulnig TM, Huber J, Leitinger N, Imre EM, Angelisova P, Nowotny P, et al., 2001 Polyunsaturated eicosapentaenoic acid displaces proteins from membrane rafts by altering raft lipid composition. J. Biol. Chem 276, 37335-40. [PubMed: 11489905]

Su F, Yi H, Xu L, Zhang Z, 2015 Fluoxetine and S-citalopram inhibit M1 activation and promote M2 activation of microglia in vitro. Neuroscience. 294, 60-8. [PubMed: 25711936]

Sublette ME, Ellis SP, Geant AL, Mann JJ, 2011 Meta-analysis of the effects of eicosapentaenoic acid (EPA) in clinical trials in depression. J. Clin. Psychiatry

Sublette ME, Hibbeln JR, Galfalvy H, Oquendo MA, Mann JJ, 2006 Omega-3 polyunsaturated essential fatty acid status as a predictor of future suicide risk. Am. J. Psychiatry 163, 1100-2. [PubMed: 16741213]

Teti GL, Rebok F, Rojas SM, Grendas L, Daray FM, 2014 Systematic review of risk factors for suicide and suicide attempt among psychiatric patients in Latin America and Caribbean. Rev. Panam. Salud Publica 36, 124-33. [PubMed: 25345534]

Tian Q, Grzemski FA, Panagiotopoulos S, Ahokas JT, 2006 Peroxisome proliferator-activated receptor alpha agonist, clofibrate, has profound influence on myocardial fatty acid composition. Chem. Biol. Interact 160, 241-51. [PubMed: 16540100]

Tiemeier H, van Tuijl HR, Hofman A, Kiliaan AJ, Breteler MM, 2003 Plasma fatty acid composition and depression are associated in the elderly: the Rotterdam Study. Am. J. Clin. Nutr 78, 40-6. [PubMed: 12816769]

Tondo L, Baldessarini RJ, Hennen J, Minnai GP, Salis P, Scamonatti L, et al., 1999 Suicide attempts in major affective disorder patients with comorbid substance use disorders. J. Clin. Psychiatry 60 Suppl 2, 63-9; discussion 75-6, 113-6. [PubMed: 10073390]

Tousoulis D, Psarros C, Demosthenous M, Patel R, Antoniades C, Stefanadis C, 2014 Innate and adaptive inflammation as a therapeutic target in vascular disease: the emerging role of statins. J. Am. Coll. Cardiol 63, 2491-502. [PubMed: 24613322]

Vainio S, Jansen M, Koivusalo M, Rog T, Karttunen M, Vattulainen I, et al., 2006 Significance of sterol structural specificity. Desmosterol cannot replace cholesterol in lipid rafts. J. Biol. Chem 281, 348-55. [PubMed: 16249181]

van Heeringen K, Mann JJ, 2014 The neurobiology of suicide. The lancet. Psychiatry 1, 63-72. [PubMed: 26360403]

Van Orden KA, Witte TK, Cukrowicz KC, Braithwaite SR, Selby EA, Joiner TE, Jr., 2010 The interpersonal theory of suicide. Psychol. Rev 117, 575-600. [PubMed: 20438238]

Vaz JS, Kac G, Nardi AE, Hibbeln JR, 2014 Omega-6 fatty acids and greater likelihood of suicide risk and major depression in early pregnancy. J. Affect. Disord 152-154, 76-82. 
Vazquez M, Alegret M, Lopez M, Rodriguez C, Adzet T, Merlos M, et al., 1995 Different effects of fibrates on the microsomal fatty acid chain elongation and the acyl composition of phospholipids in guinea-pigs. Br. J. Pharmacol 116, 3337-43. [PubMed: 8719816]

Williams JA, Batten SE, Harris M, Rockett BD, Shaikh SR, Stillwell W, et al., 2012 Docosahexaenoic and eicosapentaenoic acids segregate differently between raft and nonraft domains. Biophys. J 103, 228-37. [PubMed: 22853900]

Wong SW, Kwon MJ, Choi AM, Kim HP, Nakahira K, Hwang DH, 2009 Fatty acids modulate Tolllike receptor 4 activation through regulation of receptor dimerization and recruitment into lipid rafts in a reactive oxygen species-dependent manner. J. Biol. Chem 284, 27384-92. [PubMed: 19648648]

World Health Organization. Preventing suicide: A global imperative. Geneva 2014.

World Health Organization. Global Burden of Disease (GBD). 2017.

Wu S, Ding Y, Wu F, Xie G, Hou J, Mao P, 2016 Serum lipid levels and suicidality: a meta-analysis of 65 epidemiological studies. J. Psychiatry Neurosci 41, 56-69. [PubMed: 26505144]

Yang JR, Han D, Qiao ZX, Tian X, Qi D, Qiu XH, 2015 Combined application of eicosapentaenoic acid and docosahexaenoic acid on depression in women: a meta-analysis of double-blind randomized controlled trials. Neuropsychiatr Dis Treat. 11, 2055-61. [PubMed: 26300645]

Yu Z, Huang T, Zheng Y, Wang T, Heianza Y, Sun D, et al., 2017 PCSK9 variant, long-chain n-3 PUFAs, and risk of nonfatal myocardial infarction in Costa Rican Hispanics. Am. J. Clin. Nutr 105, 1198-203. [PubMed: 28330911] 


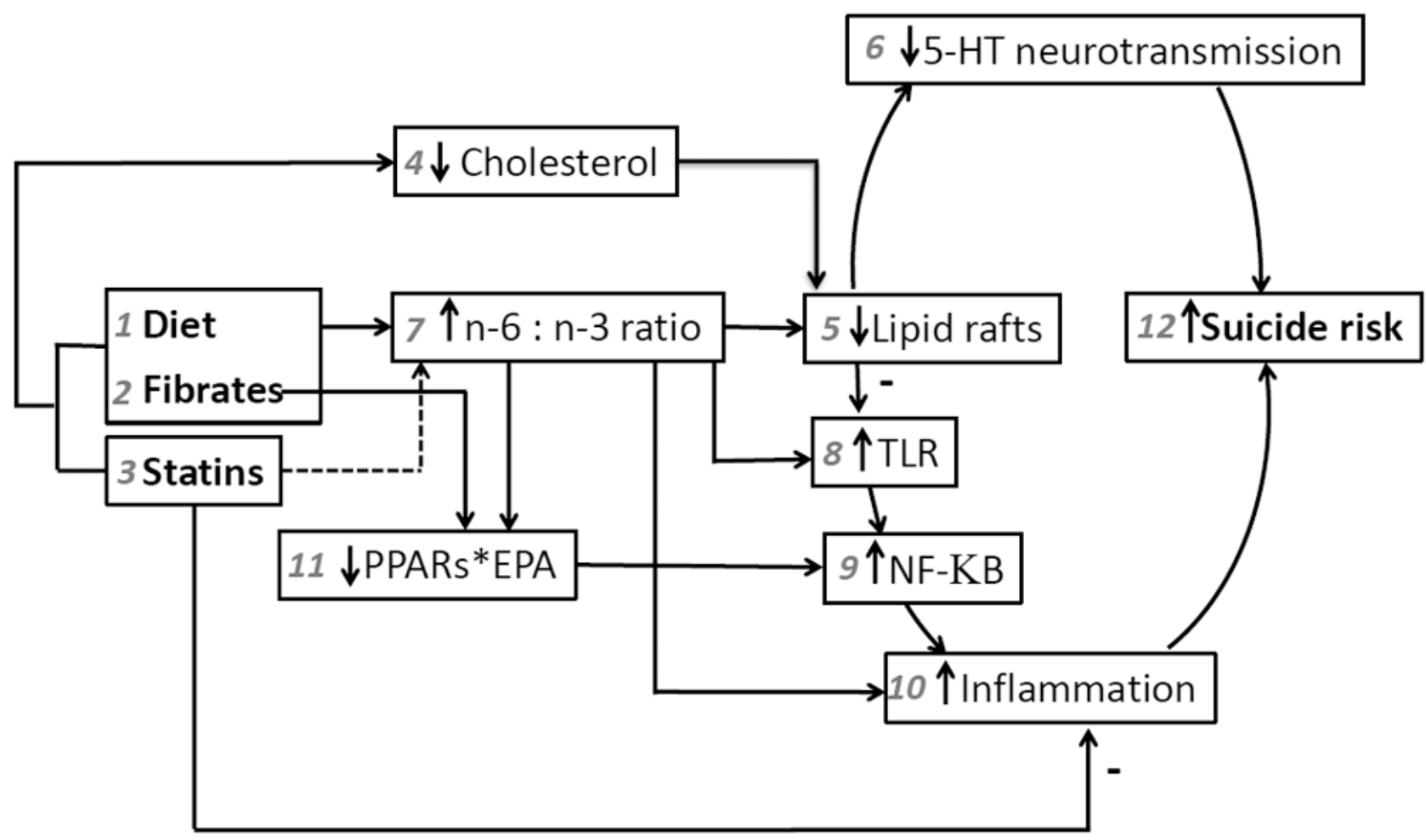

Figure 1. Theoretical schematic of pathways through which an elevated n-6 to n-3 PUFA ratio could affect suicide risk.

Treatment with (1) diet, (2) fibrates and (3) statins that lower (4) cholesterol can cause (5) disruption of lipid rafts with functional consequences, due to lipid raft regulation of serotonin transporters and receptors, resulting in (6) decreased serotonergic neurotransmission, which has been shown to increase (12) suicide risk. (1) Diets replacing saturated fats with polyunsaturated oils high in n-6 PUFAs and (2) fibrates also can cause an increase in ( 7 ) the ratio of n- 6 to $n-3$ PUFAs. This is, effectively, a lowering of $n-3$ that also is expected to contribute to (5) destabilization of lipid rafts, although directional effects of PUFAs on lipid rafts are complex and incompletely understood. More clearly, a higher n-6 to n-3 PUFA ratio directly promotes (10) inflammation, which is associated with (12) suicide risk. Also, lower n-3 PUFAs can indirectly result in increased inflammation by lowering DHA-mediated inhibition of (8) TLR dimerization and activation, resulting in downstream increased activation of (9) NF-KB, a (10) pro-inflammatory molecule. Either (1) decreased n-3 intake or (2) fibrate competition with EPA can reduce EPA binding to PPARs. Since (11) the EPA*PPARs complex acts as a brake on (9) NF-KB, interference with the EPA*PPARs complex via both mechanisms also contributes to activation (disinhibition) of (9) NF-KB. Counter to these pro-inflammatory forces, (5) decreased lipid raft functioning could decrease (8) TLR recruitment into lipid rafts and activation; and (3) statins may have lesser effects on (7) the n-6 to n-3 ratio and they also exert pleiotropic (10) anti-inflammatory effects that may mitigate (12) suicide risk. See text for all references substantiating these relationships. 